\title{
Pelatihan Strategi Peningkatan Pemasaran, Penjualan dan Pelaporan Akuntansi melalui Pembuatan Website di Yayasan Duta Bangsa Indonesia di Cikarang
}

\author{
Cahyadi Husadha ${ }^{1,{ }^{*}}$, Widi Winarso ${ }^{1}$, Wastam Wahyu Hidayat ${ }^{1}$, Wirawan Widjanarko ${ }^{1}$, \\ Adelina Suryati ${ }^{1}$, Adi Wibowo Noer Fikri ${ }^{1}$ \\ ${ }^{1}$ Fakultas Ekonomi, Universitas Bhayangkara Jakarta Raya; Jl. Raya Perjuangan, Marga \\ Mulya, Bekasi Utara, Jawa Barat 17121. Telp: 021-88955882, 889955883, e-mail: \\ cahyadi.husadha@dsn.ubharajaya.ac.id; e-mail: widi.winarso@dsn.ubharajaya.ac.id; e-mail: \\ wastam.wahyu@dsn.ubharajaya.ac.id; e-mail:wirawan.widjanarko@dsn.ubharajaya.ac.id; e- \\ mail: adelina.suryati@ubharajaya.ac.id; e-mail: adi.wibowo@dsn.ubharajaya.ac.id
}

* Korespondensi: e-mail: cahyadi.husadha@dsn.ubharajaya.ac.id

\begin{abstract}
Duta Bangsa College of Technology was established on March 3, 2007 in accordance with the Decree of the Minister of Education and Culture Number.34/D/0/2007 concerning the establishment of STT.Duta Bangsa. STT.Duta Bangsa is located in Kp. Pulokapuk RT 01 RW 05 Mekar Mukti Village Kec. North Cikarang Kab. Bekasi. Tel/Fax number: (021) 29082747. Permit of Higher Education: Minister of Education Decree No.2740/D/T/K-IV/2010. Minister of Education Decree No.2741/D/T/K-IV/2010. Decree of Minister of National Education No.2742/D/T/K-IV/2010. The problem faced by the Indonesian ambasadors foundation is the marketing problem, where they have to compete in fighting over a limited market niche with more and more competitors. Moreover, the market share to fight over the students who are nota bene is the X generation who are literate in the world of Information Technology, which certainly requires marketing to hit their hearts. Starting from this, we from the Faculty of Economics at Bhayangkara University offered to provide training for Marketing Persons at the Duta Bangsa Foundation so that they could win a large market share of students in Bekasi, especially in the Cikarang area, in creating a web site.
\end{abstract}

Keywords: Increasing the number of students, website

\begin{abstract}
Abstrak
Sekolah Tinggi Teknologi Duta Bangsa Berdiri Tanggal 3 Maret tahun 2007 sesuai dengan Keputusan Mentri Pendidikan dan Kebudayaan Nomor.34/D/0/2007 Tentang berdirinya STT.Duta Bangsa. STT.Duta Bangsa berlokasi di Kp. Pulokapuk RT 01 RW 05 Desa Mekar Mukti Kec. Cikarang Utara Kab. Bekasi. No telp/Fax: (021) 29082747. Ijin Dikti: SK Mendiknas No.2740/D/T/K-IV/2010. SK Mendiknas No.2741/D/T/K-IV/2010. SK Mendiknas No.2742/D/T/KIV/2010.Masalah yang dihadapi oleh yayasan Duta bangsa Indonesia adalah masalah pemasaran, dimana mereka harus bersaing dalam memperebutkan ceruk pasar yang terbatas dengan pesaing yang makin banyak. Terlebih pangsa pasar untuk memperebutkan mahasiswa yang nota bene adalah generasi $X$ yang melek dunia Information Technologi tentu membutuhkan pemasaran yang lebih mengena dihati mereka. Bertolak dari hal tersebut, kami dari Fakultas Ekonomi Universitas Bhayangkara menawarkan diri untuk memberi pelatihan bagi Insan Pemasaran di Yayasan Duta Bangsa supaya bisa merebut sebesar besarnya pangsa pasar mahasiswa di bekasi utamanya di wilayah Cikarang dalam membuat web site.
\end{abstract}

Kata kunci: Peningkatan Jumlah Mahasiswa, website 


\section{Pendahuluan}

Salah satu hal penting dalam suatu bisnis adalah pemasaran atau marketing, karena disini merupakan ujung tombak dari kelangsungan suatu bisnis atau usaha. Bicara mengenai pemasaran tentu kita akan mcari cara bagaimana agar produk atau jasa yang kita tawarkan semakin dikenal oleh masyarakat secara luas. Oleh karena itu diperlukanya beberapa media promosi untuk memperkenalkan produk atau jasa yang kita tawarkan, seperti Televisi, Radio, Koran, dan Website. Dengan adanya media pemasaran yang semakin banyak akan memungkinkan produk kita semakin dikenal semakin luas. Pada pembahasan kali ini kita akan mengulas mengenai media pemasaran melalui online khususnya website.

Website merupakan media promosi yang sangat efisien dan ekonomis, selain itu dengan website kita bisa menjaring custommer dimanapun dan kapanpun. Website memiliki banyak sekali kelebihan jika dibandingkan dengan media pemasaran yang lain, berikut ini akan kita bahas mengenai kelebihan media pemasaran melalui website dibanding dengan media pemasaran yang lainya.

\section{Biaya Murah}

Mengingat pentingnya pemasaran dalam suatu bisnis kita tentu akan berusaha bagai mana agar kita bisa mendapatkan target pasar yang seluas luasnya dengan biaya sang seminim mungkin. Karena itu website ini merupakan media yang sagat cocok karena biayanya sangat murah dan jangkauan pasar yang sangat luas. Kita cukup menganggarkan biaya mulai dari 350ribu per tahun maka produk atau jasa yang Kita tawarkan bisa di akses dari manapun dan kapanpun selama ada koneksi internet.

\section{Pengelolaan Mudah}

Perkembangan zaman semakin canggih begitu juga dengan perkembangan website yang saat ini semakin mudah untuk dikelola cukup dengan menggunakan smartphone Kita. Dengan adanya CMS saat ini Kita tidak perlu menguasai bahasa pemrograman untuk memiliki website yang profesioal. Sesekali kita cukup memosting produk baru kita di website dengan menggunakan HP itu sudah cukup, bagai mana, mudah bukan?

\section{Tepat Sasaran}

Website dilengkapi dengan SEO dari situ kita bisa memilih target market untuk pemasaran produk atau jasa kita. Seo merupakan cara yang paling murah dan sangat efektif, kita bisa riset kata kunci yang berhubungan dengan produk atau jasa kita untuk menjaring konsumen baru. Namun untuk memaksimalkan SEO ini memakan waktu, tapi tidak usah khawatir, ID programmer juga menyediakan jasa SEO dengan biaya terjangkau.

Untuk itulah fakultas Ekonomi Program studi Akuntansi Universitas Bhayangkara Jaya memberikan pelatihan sebagai wujud Tri Dharma Perguruan Tinggi pada pengabdian kepada masyarakat dalam bentuk "Pelatihan Strategi Peningkatan Pemasaran dan Penjualan melalui Pembuatan Web Site E-Comerce. 


\section{Commodity Exchanges}

Perbedaan yang mendasar antara pasar konvensional dengan e-Marketplace jenis ini adalah pada konsep transparansi.Di sisi pembeli (buyer transparency), besar sekali manfaat yang diperoleh jika bertransaksi di pasar ini karena melalui internet harga-harga produk maupun jasa dapat secara transparan diketahui. Artinya, karena begitu banyaknya pemasok (suppliers) produk atau jasa yang sama, maka seorang calon pembeli dapat melakukan pengecekan dan perbandingan antara masing-masing harga yang ditawarkan tersebut, tentu saja dengan tujuan untuk mencari harga termurah.

Selain harga, transparansi terhadap kualitas pelayanan, aturan garansi, fasilitas asuransi, dan jaminan pelayanan purna jual merupakan beberapa hal yang dapat pula diperbandingkan keberadaannya oleh para calon pembeli.Untuk produk-produk khusus, dimana tidak banyak pemasok yang menawarkannya, aspek transparansi dapat pula terlihat, karena pembeli dapat melakukan perhitungan tersendiri mengenai tingkat kewajaran harga yang ditawarkan pemasok tersebut (karena pada dasarnya sebuah perusahaan harus melalui beberapa tahap aktivitas/proses penciptaan produk yang dengan mudah dapat dihitung biayanya per tahap melalui pengecekan lansung di internet).

\section{Value Added Services}

Perkembangan berikutnya dari e-Marketplace akan menuju kepada terbentuknya sebuah arena dimana terciptanya sebuah bentuk penawaran $\neg$ penawaran baru terhadap sebuah metode jual-beli yang belum/sulit terjadi di pada pasar konvensional (value added services). Filosofi utama yang mendasari jenis perdagangan ini adalah suatu pkitangan yang mengatakan bahwa setiap konsumen (atau calon pembeli) adalah unik, sehingga mereka sebenarnya mengharapkan untuk memperoleh atau dapat membeli produk atau jasa yang khusus sesuai dengan kebutuhan atau kesukaan masing-masing individu.

\section{Knowledge Networks}

Perkembangan berikutnya dari e-Marketplace adalah menuju ke sebuah komunitas yang berbasis pengetahuan (knowledge). Perusahaan adalah merupakan kumpulan dari sumber daya manusia dengan kompetensi dan keahlian yang beragam.Interaksi antara perusahaan dengan mitra bisnis, stakeholder (yang berkepentingan), dan konsumen tidak hanya merupakan sebuah komunikasi pasif belaka, namun di dalamnya terkandung aspek-aspek pengetahuan yang secara sadar atau tidak saling dipertukarkan.Lihatlah bagaimana dengan hanya berbekal fasilitas browsing dan situs-situs portal, seseorang yang sangat awam di bidang tertentu dalam waktu singkat dapat memiliki berbagai referensi berharga berkualitas tinggi untuk dipelajari. Tidak pernah terbayangkan sebelumnya bahwa hanya dengan berbekal email dan situs (homepage), seorang individu dapat mengembangkan bisnis dengan berbagai sumber daya data dan informasi yang telah tersedia gratis di internet. 


\section{Metode Pelaksanaan}

Untuk menunjang kegiatan pengabdian masyarakat ini maka digunakan metode yang mendukung pelaksanaan kegiatan tersebut. Berikut ini adalah rincian metode pelaksanaan yang akan dilakukan yaitu: 1) Metode Pengumpulan data. Hal ini digunakan untuk mengumpulkan data-data mengenai kegiatan yang dilakukan oleh pihak kampus bersama dengan jajaran yang terkait pemda yang terdapat di Yayasan Duta Bangsa Indonesia yang meliputi mengamati, mewawancarai yang meliputi survei ke kampus tersebut sehingga diperoleh hal-hal apa saja yang merupakan kebutuhan-kebutuhan dan kendala mereka; 2) Menentukan tema pengabdian yang akan diberikan. Berdasarkan atas apa yang telah dilakukan dalam survei yang diuraikan secara rinci pada latar belakang sehingga tema pengabdian dapat segera ditentukan yaitu pelatihan pembuatan website e-comerce untuk menarik jumlah mahasiswa untuk masuk ke kampus mereka; 3) Mencari Studi Pustaka. Studi pustaka adalah teknik pengumpulan data referensi dari berbagai jenis sumber keilmuan yang menunjang permasalahan yang sedang dicarikan solusinya. Dalam kegiatan pengabdian masyarakat ini, berbagai teori dan implementasi tentang website dieksplorasi untuk dapat memberikan pemahaman yang signifikan; 4) Membuat materi pelatihan. Berdasarkan studi pustaka yang telah dilakukan maka dibuatlah materi pelatihan yang dibuatkan kedalam modul pelatihan pembuatan website e-comerce; 5) Menyajikan pelatihan. Pelatihan diberikan secara tutorial antara instruktur dengan peserta yang langsung didemokan pada peserta pengabdian masyarakat.

Luaran yang akan dihasilkan dari pelatihan pembuatan Web site bagi bagian pemasaran Yayasan Duta Bangsa Indonesia adalah: 1) Memberikan jasa berupa pemahaman dan pengertian tentang pemasaran dengan menggunakan website; 2) Memberikan jasa berupa pelatihan pembuatan website e-comerce yang dapat meningkatkan minat mahasiswa generasi milenial ke kampus mereka; 3) Memberikan dampak pada kegiatan pengembangan ilmu, wawasan dan pengetahuan kepada binaan sehingga mereka dapat meningkatkan wawasan dan ketrampilannya dalam bidang information technologi melalui pembuatan website untuk meningkatkan jumlah penerimaan mahasiswa baru.

\section{Hasil dan Pembahasan}

\section{A. E-market Place}

Pasar (elektronik atau bukan) memiliki 3 fungsi, yaitu: 1). Menyamakan minat pembeli dan penjual. 2). Memfasilitasi pertukaran informasi, barang, jasa, dan pembayaran yang juga diasosiasikan sebagai transaksi pasar. 3). Menyediakan ifrastruktur institusional, seperti hukum, kebutuhan regular, yang memungkinkan fungsi yang efisien bagi pasar.

Dunia maya yang tercipta karena berkembangnya teknologi internet, secara tidak langsung membentuk sebuah pasar atau arena perdagangan tersendiri yang kerap dinamakan sebagai e-Marketplace (beberapa praktisi manajemen menyebutnya sebagai Marketspace). Sebagaimana pasar dalam pengertian konvensional, yaitu tempat bertemunya penjual dan 
pembeli, di dalam e-Marketplace berinteraksi pula berbagai perusahaan-perusahaan di dunia tanpa dibatasi oleh teritori ruang (geografis) maupun waktu.

Dari munculnya e-marketplace, terutama internet, merubah beberapa hal dalam proses untuk trading dan supply chain. Perubahan ini yang dimotori oleh IT menghasilkan:

a) Informasi yang lebih bagus dalam lingkungan bertransaksi \&berhubungan.

b) Biaya untuk mencari informasi yang lebih rendah untuk pembeli.

c) Menghilangkan informasi yang membingungkan bagi penjual dan pembeli.

d) Pemisahan sementara yang lebih baik antara waktu pembelian dengan waktu pemprosesan produk digital yang dibeli di e-marketplace.

e) Pembeli dan penjual bisa berada di tempat yang berbeda.

Di dalam dunia maya, secara prinsip, e-Marketplace berkembang melalui empat tahapan evolusi berdasarkan konsep yang dikembangkan oleh Warran D. Raisch. Keempat tahapan evolusi tersebut masing-masing adalah: Commodity Exchanges, Value-Added Services, Knowledge Networks, Value Trust Networks.

\section{B. Tema Pengabdian}

Berdasarkan atas apa yang telah dilakukan dalam program pengabdian kepada masyarakat tersebut, maka tema dalam kegiatan pengabdian lanjutan ini adalah "Pelatihan Strategi Peningkatan Pemasaran, Penjualan dan Pelaporan Akuntansi melalui Pembuatan Website di Yayasan Duta Bangsa Indonesia di Cikarang."

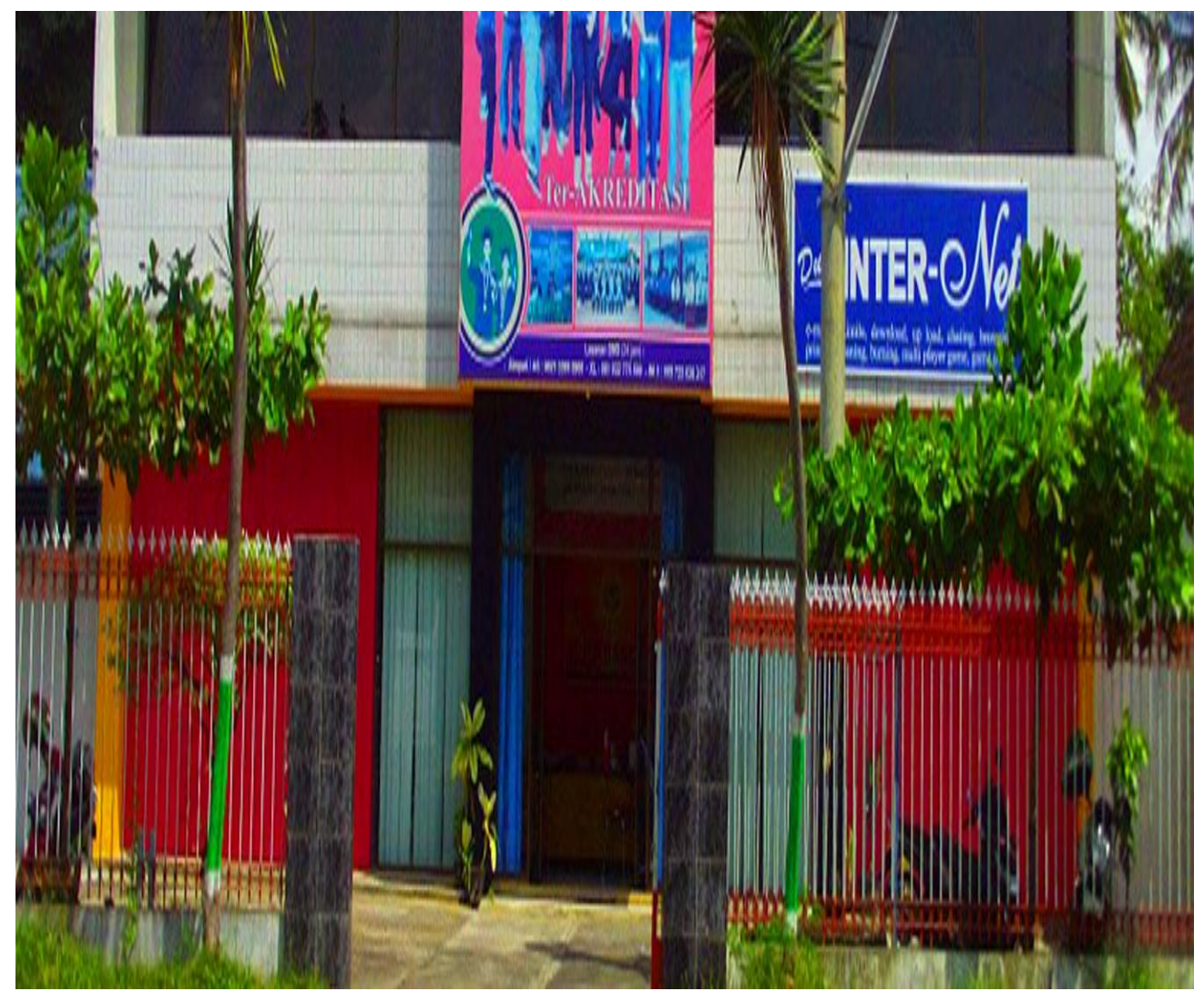

Sumber: Hasil Pelaksanaan (2020)

Gambar 1. Photo Kampus STT Duta Bangsa di Cikarang 

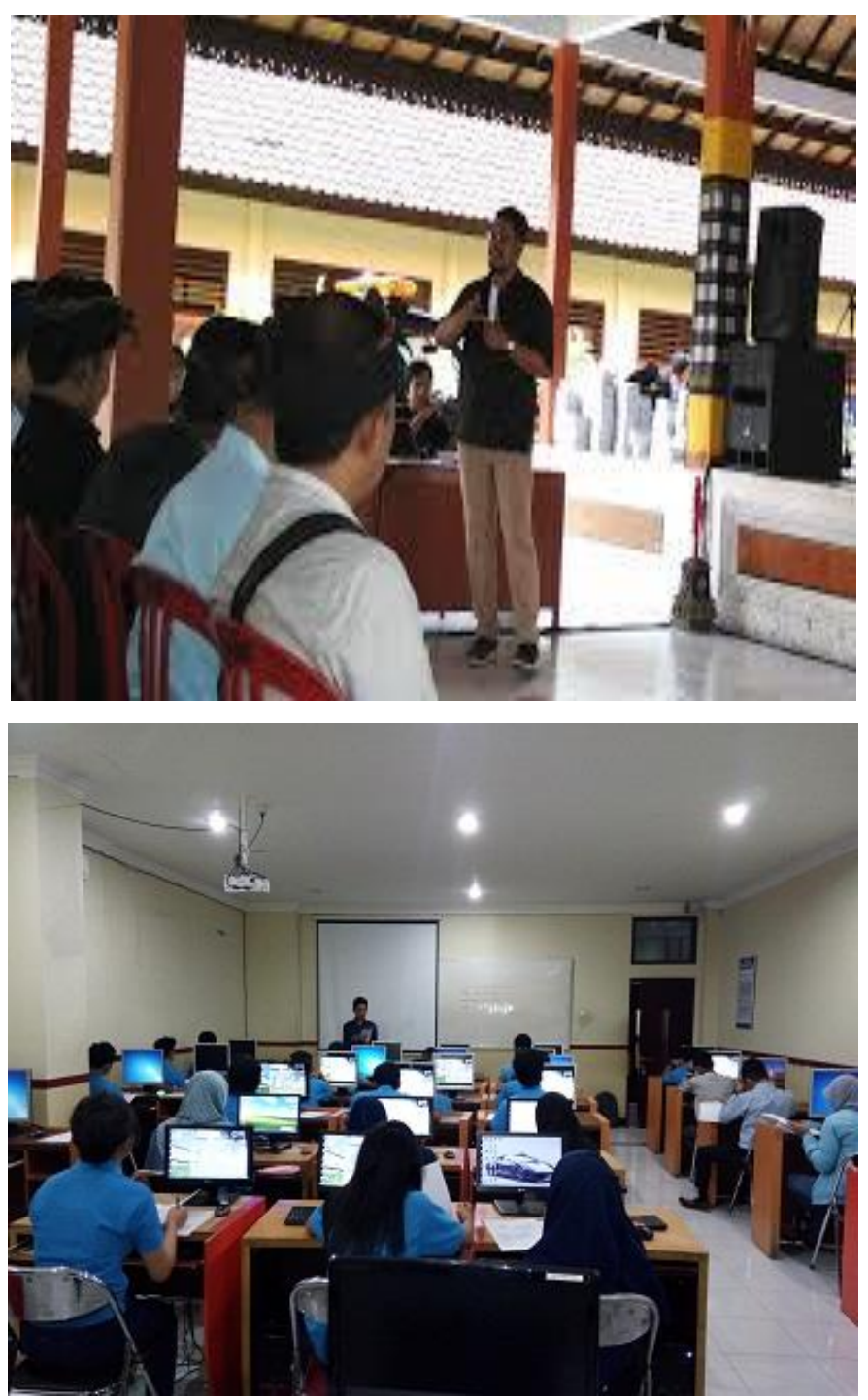

Sumber: Hasil Pelaksanaan (2020)

Gambar 2. Photo Kegiatan Penyampaian Materi PkM

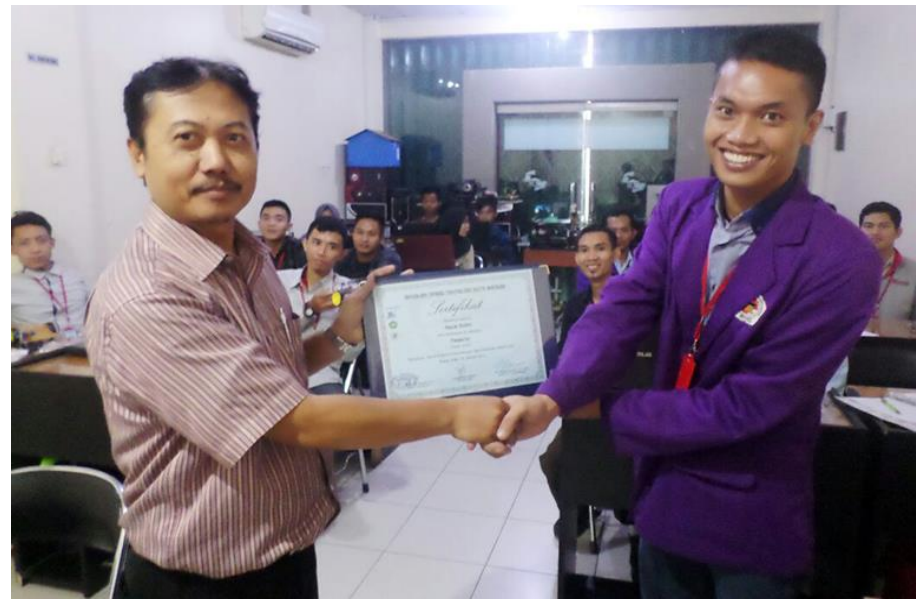

Sumber: Hasil Pelaksanaan (2020)

Gambar 3. Photo Kegiatan Seminar Kewirausahaan 


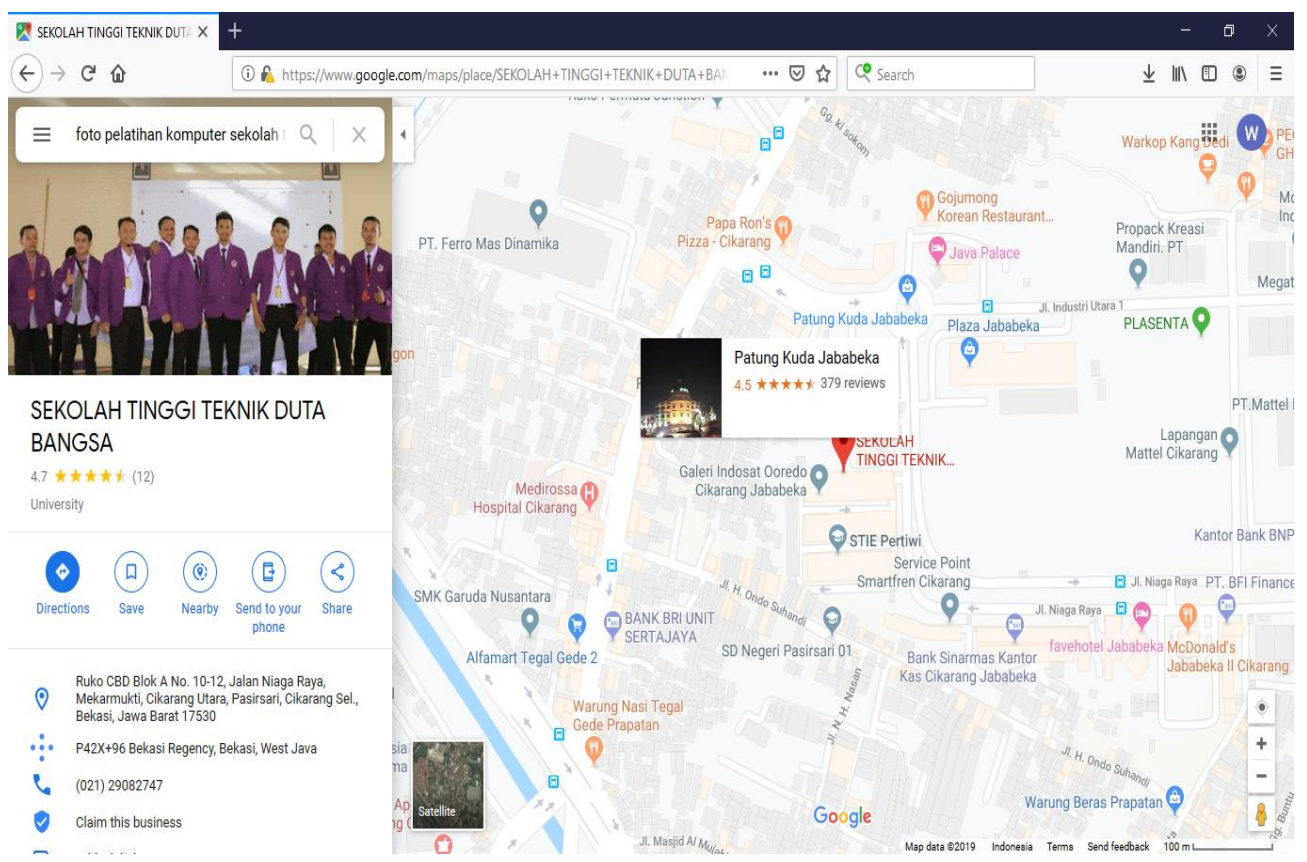

Sumber: Hasil Pelaksanaan (2020)

Gambar 4. Lokasi Kegiatan PkM Kampus STT Duta Bangsa di Cikarang di MAP

\section{Materi Pelatihan}

Dengan adanya kegiatan pengabdian kepada masyarakat yang diselenggarakan oleh prodi Akuntansi pada Fakultas Ekonomi Universitas Bhayangkara Jaya ini yaitu tentang Pelatihan pembuatan Laporan Keuangan maka diharapkan dapat membantu.

1) Meningkatkan Kredibilitas Usaha Kecil

Hampir semua kalangan konsumen dewasa ini semakin banyak yang menggunakan internet untuk mencari produk atau layanan yang mereka butuhkan.

2) Menghemat Uang

Sebagai pemilik usaha, kita mungkin berpikir bahwa Kita belum mampu membuat sebuah website yang profesional.

3) Selalu Terhubung Dengan Pelanggan

Coba bayangkan website Kita sebagai brosur online atau katalog. Adalah jauh lebih mudah dan cepat untuk memperbarui informasi tentang produk dan layanan di situs kita daripada dalam bahan cetak, sehingga ini adalah cara yang efektif untuk menginfokan kepada pelanggan kita tentang kedatangan produk baru, acara mendatang, promosi khusus, atau layanan baru yang sedang Kita tawarkan.

4) Mudah Diakses

Sebuah website bisa diakses oleh Kita sendiri dan pelanggan potensial selama 24 jam sehari, 7 hari seminggu, dan 365 hari dalam setahun.

5) Menjangkau Target Pasar Yang Lebih Luas 
Baik menjual produk maupun jasa, website akan selalu menjadi tempat alternatif yang menarik untuk mempromosikannya.

6) Sarana Katalog Produk dan Jasa (Portofolio)

Tidak peduli apa pun jenis usaha yang kita jalani, sebuah situs web adalah tempat yang bagus untuk memperlihatkan karya kita.

7) Menghemat Waktu

Memberikan informasi kepada pelanggan pasti membutuhkan waktu, baik itu lewat telepon, bertatap muka, melalui brosur, ataupun dalam email.

8) Meningkatkan Pelayanan Pada Pelanggan

Mungkin kita seorang akuntan dan ingin memberikan nasihat kepada klien Kita tentang cara untuk menyederhanakan praktik pembukuan mereka. Nah, dengan menambahkan halaman tanya jawab, menulis artikel dan blog, atau memberikan info newsletter untuk menjawab semua pertanyaan pelanggan Kita, hal tersebut dapat membuat para pelanggan selalu upto-date.

\section{Indikator Keberhasilan Kegiatan PKM}

Jika rencana kegiatan sama dengan pelaksanaan di lapangan, berarti dapat dikatakan sesuai dengan yang diharapkan atau dapat dikatakan berhasil. Ada beberapa indikator keberhasilan dalam penyelenggaraan kegiatan PKM yaitu:

a) Tanpa website, pelanggan potensial akan pergi ke pesaing kita yang memiliki website. Jika kita sudah memiliki situs web tetapi masih apa adanya, ada baiknya kita desain ulang dengan tampilan yang lebih profesional, sehingga akan memberikan tingkat kepercayaan yang lebih besar pada bisnis Kita.

b) Tanpa website, pelanggan potensial akan pergi ke pesaing kita yang memiliki website. Jika coba bandingkan dengan biaya iklan di surat kabar, ketika Kita bisa melihat pasar potensial yang dapat Kita capai dengan website, itu adalah cara yang sangat efektif untuk mempromosikan bisnis Kita. Meskipun biaya membangun website itu bervariasi, sebuah situs web untuk usaha kecil umumnya berbiaya di bawah Rp500.000 per bulan. Dan akan jauh lebih hemat lagi jika dikonversikan per tahunan.

c) Tidak seperti iklan cetak yang cepat menjadi usang, situs web kita dapat memberikan informasi yang senantiasa up-to-date.

d) Mereka bisa dengan nyaman melihat produk dan jasa Kita ketika toko atau kantor offline ditutup. Dengan gaya hidup yang selalu sibuk di masa kini, ini adalah selling point yang besar ketika membuat keputusan pembelian.

e) Sebagai penjual eceran suatu produk, sebuah situs web eCommerce adalah tempat yang bagus untuk mempromosikan produk Kita ke pasar yang lebih luas, karena produk Kita bisa diakses dan dilihat secara global.

f) Dengan memasukkan portofolio atau galeri foto produk, serta testimonial tentang pekerjaan kita, kita dapat menunjukkan apa yang membuat bisnis kita unik. 
g) Dengan katalog online, Kita dapat memberikan banyak informasi tentang produk dan jasa Kita.

h) Bagi kami selaku dosen-dosen peyelenggara pengabdian masyarakat ini adalah merupakan wujud pengimplementasian dari tri dharma perguruan tinggi yang merupakan bentuk pengabdian kami kepada masyarakat khususnya dalam hal ini pada para pemasar di Yayasan Duta Bangsa Indonesia.

\section{Kesimpulan}

Berdasarkan hasil pelaksanaan kegiatan PKM yang telah dilakukan, dapat diambil beberapa kesimpulan sebagai berikut: a). Telah dilakukan Pelatihan Kerajinan Tangan di STTD Duta Bangsa. b). Peserta sangat antusias dengan Materi Pelatihan yang diberikan oleh pemateri. c). Peserta dapat meningkatkan pengetahuan sekaligus sebagai stimulus agar peserta pelatihan lebih kreatif, inovatis, maju, berkembang, dan sanggup dalam membuat materi dan tugas perkuliahan.

Dalam keterbatasan waktu dan pengelolan, tim menyadari waktu dan biaya untuk pelatihan ini masih harus terus ditingkatkan untuk kegiatan PkM ini. Salah satu bukti dalam pelaksanaan PkM adalah berbagi pengetahuan, pengalaman, dan berbagai studi literature untuk dijadikan sebagai panduan dan pedoman dalam hidup. Sehingga, Rrencana dalam tahapan kegiatan PkM berikutnya adalah sebagai berikut: a). Pelatihan terapan dan refleksi ECommers. b). Produk-produk E-Commers harus dan perlu untuk di buatkan HAKI agar menjadi paten tersendiri bagi peserta sebagai kebanggaan dan modal untuk mendapatkan royalti. c). Perlu untuk adanya pelatihan pengembangan marketing untuk memasarkan produk-produk dengan modifikasi tampilan internet dari ketrampilan kerajinan tangan yang peserta kuasai dan berhasil untuk diterapkan. d). Menjadi hal yang sangat mungkin dalam hal kewajiban dosen untuk melaksanakan tri dharma perguruan tinggi bagi dosen atas kewajibannya sebagai dosen, untuk melakukan kegiatan PkM sebagai tempat binaan dosen dalam mengembangkan keilmuannya.

\section{Ucapan Terima Kasih}

Secara khusus rasa terimakasih tersebut kami sampaikan kepada:

1. Irjen. Pol. (Purn) Dr. Drs. H. Bambang Karsono, S.H., M.M. selaku Rektor Universitas Bhayangkara Jakarta Raya yang telah memberikan arahan dan semangat bagi para Dosen untuk terus melakukan Penelitian dan Pengabdian Kepada Masyarakat demi kemajuan di Universitas Bhayangkara Jakarta Raya.

2. Dr. Istianingsih, selaku Dekan Fakultas Ekonomi Universitas Bhayangkara Jakarta Raya, yang telah menyetujui untuk melakukan Pengabdian kepada masyarakat.

3. Ir. Djuni Thamrin, Ph.D. selaku Kepala Lembaga Penelitian, Pengabdian Masyarakat dan Publikasi yang telah banyak memberikan arahan serta masukan dalam penyempurnaan Laporan Hasil Pengabdian Kepada Masyarakat. 
4. Prasojo, S. Sos, M.Si. selaku Kepala Bidang Pengabdian Kepada Masyarakat dan Kewirausahaan yang telah memberikan arahan serta masukan dalam penyempurnaan Proposal Pengabdian Kepada Masyarakat.

5. Adelina Suryati, S.E., M.Ak. selaku Kepala Bagian Keuangan, Universitas Bhayangkara Jakarta Raya

6. Yayan selaku Pimpinan Rumah Yatim Cabang Kota Bekasi yang telah memberikan kesempatan kepada tim dalam melaksakan kegiatan Pengabdian Kepada Masyarakat ini.

7. Rekan-rekan Dosen yang telah memberikan masukan dan pencerahan dalam melakukan penelitian, yang tidak bisa saya sebutkan satu-satu.

\section{Daftar Pustaka}

Kemal, A, \& Sularto, L. (2001). "Introduction ToE-Marketplace" Lembaga Pengembangan Komputerisasi Universitas Gunadarma: Jakarta, Januari,

Amir, A.Y. (2017). Pengantar Akuntansi 1, Adaptasi Indonesia,Salemba Empat.

Purbayu, A. (2014). Toko Online dengan Php dan Mysql. Jakarta:Elex Media Komputindo

Rejeki, R.S.A, Utomo, A.P, \& Susanti, S.S. (2011). Perancangan dan Pengaplikasian Sistem Penjualan pada "Distro Smith" Berbasis E-Commerce.Jurnal Teknologi Informasi DINAMIK Volume 16, No.1.Universitas Stikubank.ISSN: 0854-9524 